\title{
Pavia symposium on embryos and stem cells
}

\author{
M. Boiani, ${ }^{1}$ N. Crosetto, ${ }^{2}$ C.A. Redi ${ }^{3}$
}

\begin{abstract}
${ }^{1}$ Max-Planck Institute for Molecular Biomedicine, Münster, Germany; ${ }^{2}$ Goethe University Hospital, Frankfurt am Main, Germany; ${ }^{3}$ Fondazione IRCCS Policlinico San Matteo, Pavia, Italy
\end{abstract}

Stem cells occur in very small numbers in adult tissues, in higher numbers in the fetus and its annexes and they can be derived from whole embryos or parts thereof. For a couple of years, stem cells can also be derived straight from somatic cells by retrovirus-mediated transfer of selected genes in culture. Stem cells have varying capacities for self-renewal and differentiation according to their origin, up to the point that they can be propagated in vitro for years and give rise to a wide range of cell types. This makes them suitable means for cell and tissue-replacement therapies. Gaining access to stem cells involves manipulation of living organisms i.e. human beings or animal models. The extent of manipulation ranges from the mere biopsy and culture of body cells in vitro, to their genetic manipulation and back-grafting in vivo. This raises bioethical issues as to whether we should manipulate animal and in particular human life. Many scientific meetings have been organized to present research findings on stem cells and on their potency, differentiation and therapeutic applications for treating disease. In many of these meetings, the 'mother' of all stem cells - the embryo - has often been ignored, because embryonic stem cells do not exist as such in the embryo and because the manipulation of the embryo brings up ethical concerns. To make up for this omission, the theme of our meeting was 'Pluripotency and differentiation in embryos and stem cells'. With a strong sense of purpose and commitment, we managed to hold a two-day symposium concerned with three major topics: 1) natural and induced pluripotency; 2) mechanisms of cell fate control; 3) adult and cancer stem cells. The meeting took place on January $17^{\text {th }}-18^{\text {th }} 2008$ in the beautiful, frescoed halls of Collegio Ghislieri and Borromeo, two foremost colleges in the Pavia campus. A small but prominent group of scientists took part in the meeting - James Adjaye (Germany), Anne Grete Byskov (Denmark), Jose Cibelli (USA), Ruggero De Maria (Italy), Stephen Minger (UK), Maurilio Sampaolesi (Belgium), Hans Schöler (Germany),
Giuseppe Testa (Italy), Catherine Verfaillie (Belgium) and Magdalena Zernicka-Goetz (UK). Here, we present the organizers' perspective on the meeting. It goes without saying that we may not have rendered the contents the same way as the speakers did, but we do hope that the overall meaning was preserved. The speakers have been invited to contribute to a comprehensive account of the meeting, and we hope this report makes a good start.

\section{The lectures}

The prototype stem cell is the embryonic stem (ES) cell, first reported in mice (Martin, 1981; Evans and Kaufman, 1981) and later obtained also in humans (Thomson et al., 1998). ES cells are derived mainly from the inner cell mass (ICM) of the blastocyst stage embryo but do not exist in vivo as such. Prevalent definition of mouse ES cells as pluripotent underscores their ability to form all tissues except the trophectoderm. By falling short of totipotency, ES cells escape statutory prohibitions devised to protect the totipotent zygote. ES cell lines present similarities and quirks especially in humans. The International Stem Cell Initiative (2007) has already characterized 59 human ES cell (hESC) lines from 17 laboratories and 11 Countries. Stephen Minger, a member of the Initiative, explained during the meeting that there is a core set of features common to all lines, but that there are also unexplained differences. To these differences may contribute various factors including the genetic background of hESCs and the culture conditions. Typically, ES cells are grown on feeder cells (e.g. embryonic fibroblasts). James Adjaye showed that the ability of mouse embryonic fibroblasts from different strains of mice to support hESC pluripotency depends chiefly on one component, FGF2. This growth factor stimulates the fibroblasts to secrete self-renewal supporting factors which repress differentiation-inducing activi- 
ties (Greber et al., 2007). Anne Grete Byskov showed that even within one colony of hESCs, there are regional differences in the expression of defining markers (Laursen et al., 2007). This challenges the prevalent view of clonality. The fact that ES cells can be derived from different stages of development (i.e. from blastocyst, from morula and from blastomeres) lends support to the view that ES cells are inherently heterogeneous. Heterogeneity of embryo's cells may underlie that of derivative ES cells. By tracking the cleavage pattern and thereby the position of the 2-cell progeny in mouse embryos, Magdalena Zernicka-Goetz showed that the 4-cell blastomeres are not alike in their nuclear epigenetic makeup and are not equivalent in their developmental potential (Torres-Padilla et al., 2007). These results do not counter the prevalent and well-established notion that development of mammalian embryos is highly regulative, but rather show that there is a bias. Such bias may be enhanced by expressing certain factors in a given blastomere. Using a similar approach, Hans Schöler and colleagues were able to show that a reduction of the caudal type homeo box 2 ( $C d x 2)$ gene product in the mouse blastocyst by interference RNA alters cell fate and affects ES cell derivability (Schöler, unpublished). This finding raises the possibility of restricting the embryo's potential to a specific fate only, making it unable to form a whole organism. An alternative take on the issue of garnering ES cells without creating totipotency was presented by Jose Cibelli. By activating human eggs without fertilization (parthenogenesis) or by transplanting somatic human nuclei into a host egg ooplasm from a different species (cross-species nuclear transfer), pluripotent cell lines can be derived without creating viable embryos or at least without using human oocytes (Cibelli, unpublished). So far we have dealt with ES cells that can be derived from more or less viable embryos, but do not exist as such in vivo. Unlike ES cells, adult stem cells do exist in vivo in most tissues. Compared with ES cells, tissue specific stem cells have less selfrenewal ability in vitro and, although they can differentiate into multiple lineages, they are not pluripotent. Catherine Verfaillie identified a particular cell population in bone marrow and other tissue cultures from mice, rats and humans (Jiang et al., 2002a,b). These cells have been named Multipotent Adult Progenitor Cells (MAPCs) and hold, at the single cell level and without co-culture with other cell types, multipotent differentiation and extensive proliferation potentials. MAPCs can participate in normal development after blastocyst injection and can also contribute directly to adult tissues without giving rise to teratomas. Maurilio Sampaolesi showed that bone marrow stem cells and mesangioblasts are incorporated into regenerating skeletal muscle fibers when transplanted into dystrophic mice (Pelacho et al., 2007; Cossu and Sampaolesi, 2007; Torrente et al., 2007). Unlike the classic bone marrow stem cells, there is currently no proof that MAPCs exist as such in vivo, selection markers are not yet available and the mechanism(s) underlying their culture selection is not known. In macrophages, Giuseppe Testa and colleagues showed that the $\mathrm{H} 3 \mathrm{~K} 27$ histone lysine demethylase Jmjd3 (jumonji domain containing 3) promotes extensive epigenetic rearrangements resulting in cell identity changes after a challenge with pro-inflammatory cytokines (De Santa et al., 2007). Along this train of thought, Verfaillie posits that bone marrow cells acquire greater potency during culture, possibly with an involvement of the BMP/TGF $\beta$, the Wnt-Frz and the Notch signaling pathways. It is an interesting speculation whether similar epigenetic events to the one proposed by Verfaillie and Testa may also operate in other cell types, inducing plasticity, causing instability in the cell population and leading to cancer. If so, the socalled 'cancer stem cell' (CSC) may well exist. From his studies of glioblastoma, colon and breast carcinomas, Ruggero De Maria showed that a subpopulation of $\mathrm{CD} 133^{+}$cells within the tumor, representing just a very tiny portion of the overall cancer mass, behave as cancer-initiating cells. This entails the ability to self-maintenance in an undifferentiated state in culture, to initiate tumor growth after xenotransplantation into NOD/SCID mice, and to differentiate into cancers that are phenotypically indistinguishable from the original human tumor. These CSCs represent about one in 50000 tumor cells overall, and one in $262 \mathrm{CD} 133^{+}$cells (Eramo et al., 2007; Ricci-Vitiani et al., 2007).

\section{Perspectives}

Researchers with diverse interests in developmental and stem cell biology gathered in Pavia for this meeting. The aim was to discuss natural and induced pluripotency, mechanisms of cell fate con- 
trol, and adult and cancer stem cells. It would be nice if common features or common master gene switches truly existed, as this might allow the different types of stem cells to be bundled instead of being studied one by one. Oct4 gene expression has long been regarded as one of the most defining features of pluripotent ES cells. However, Oct4expressing ES cells form tumors in vivo, while adult stem cells neither express Oct4 nor form tumors. Does this mean we have to avoid pluripotency or rather avoid Oct4 gene expression? Is pluripotency possible at all without Oct4? Or do we have to change the approach entirely, searching outside of the cell, and maybe trying to pull the strings of the signaling pathways that sense the environmental cues? In mice, cancer cells are reeducated to normal behavior when placed in a blastocyst stage embryo. This observation suggests that pluripotency and differentiation have indeed major environmental and epigenetic components and that the study of developmental and stem cell potency should be done side by side.

\section{Acknowledgements}

We would like to wholeheartedly thank the speakers for sharing their published as well as unpublished data. We thank the moderators, Juan Aréchaga (Spain) and Gianna Milano (Italy), for steering and keeping the program on track. We are greatly indebted to the Fondazione Costa (Ivrea) and Fondazione IRCCS Policlinico San Matteo (Pavia) for generously providing the financial support. We are obliged to Collegio Ghislieri and Collegio Borromeo for hosting this event. Finally, we would like to remember Anne McLaren - one of the most prominent pioneers in germ cell research, killed in car accident last year - by dedicating this symposium to her person and her science. We are sure Anne would have been pleased to join us.

\section{References}

Cossu G, Sampaolesi M. New therapies for Duchenne muscular dystrophy: challenges, prospects and clinical trials. Trends Mol Med 2007; 13:520-6.

De Santa F, Totaro MG, Prosperini E, Notarbartolo S, Testa G, Natoli $\mathrm{G}$. The histone $\mathrm{H} 3$ lysine-27 demethylase Jmjd3 links inflammation to inhibition of polycomb-mediated gene silencing. Cell 2007; 130:1083-94.

Eramo A, Lotti F, Sette G, Pilozzi E, Biffoni M, Di Virgilio A et al. Identification and expansion of the tumorigenic lung cancer stem cell population. Cell Death Differ 2007;15:504-14.

Evans MJ, Kaufman MH. Establishment in culture of pluripotential cells from mouse embryos. Nature 1981;292:154-6.

Greber B, Lehrach H, Adjaye J. Fibroblast growth factor 2 modulates transforming growth factor beta signaling in mouse embryonic fibroblasts and human ESCs (hESCs) to support hESC selfrenewal. Stem Cells 2007;25:455-64.

International Stem Cell Initiative, Adewumi 0, Aflatoonian $B$, Ahrlund-Richter L, Amit M, Andrews PW, Beighton G et al. Characterization of human embryonic stem cell lines by the International Stem Cell Initiative. Nat Biotechnol 2007;25:80316.

Jiang $Y$, Vaessen $B$, Lenvik $T$, Blackstad $M$, Reyes $M$, Verfaillie $C M$. Multipotent progenitor cells can be isolated from postnatal murine bone marrow, muscle, and brain. Exp Hematol 2002a;30:896904.

Jiang $Y$, Jahagirdar BN, Reinhardt RL, Schwartz RE, Keene $C D$, Ortiz-Gonzalez XR et al. Pluripotency of mesenchymal stem cells derived from adult marrow. Nature 2002b;418:41-9.

Laursen SB, Møllgård K, Olesen C, Oliveri RS, Brøchner CB, Byskov $A G$ et al. Regional differences in expression of specific markers for human embryonic stem cells. Reprod Biomed Online 2007;15:8998.

Martin GR. Isolation of a pluripotent cell line from early mouse embryos cultured in medium conditioned by teratocarcinoma stem cells. Proc Natl Acad Sci USA 1981;78:7634-8.

Pelacho B, Luttun A, Aranguren XL, Verfaillie CM, Prósper F. Therapeutic potential of adult progenitor cells in cardiovascular disease. Expert Opin Biol Ther 2007;7:1153-65.

Ricci-Vitiani L, Lombardi DG, Pilozzi E, Biffoni M, Todaro M, Peschle $C$ et al. Identification and expansion of human colon-cancer-initiating cells. Nature 2007;445:111-5.

Thomson JA, Itskovitz-Eldor J, Shapiro SS, Waknitz MA, Swiergiel $\mathrm{JJ}$, Marshall VS et al. Embryonic stem cell lines derived from human blastocysts. Science 1998;282:1145-7.

Torrente Y, Belicchi M, Marchesi C, Dantona G, Cogiamanian F, Pisati $F$, Gavina $M$ et al. Autologous transplantation of musclederived $\mathrm{CD} 133^{+}$stem cells in Duchenne muscle patients. Cell Transplant 2007; 16:563-77.

Torres-Padilla ME, Parfitt DE, Kouzarides T, Zernicka-Goetz M. Histone arginine methylation regulates pluripotency in the early mouse embryo. Nature 2007;445:214-8.

CarloAlberto Redi
Scientific Head
Fondazione IRCCS
Policlinico San Matteo Pavia
Viale Camillo Golgi, 19
27100 Pavia (Italy)
Tel. +39.0382.503451; Fax +39.0382 .503561
E.mail: c.redi@smatteo.pv.it

CarloAlberto Redi Scientific Head (1) 
